\title{
Chapter 25 \\ Beyond Accessibility: Transport Systems as a Societal Structure Supporting Inclusion in Late-Life
}

\author{
Anu Siren
}

\subsection{Introduction}

In their review, Walsh et al. (2017) identify transport mobility as an area in which older adults can experience social exclusion. However, transport is a cross-cutting mechanism in social exclusion: while it is interrelated with economic exclusion, it also constitutes an important element in community and spatial exclusion, as well as in exclusion from social relations, services [see Draulins and Lamura, and Cholat and Dacanto this volume] and civic participation. Thus, transport both allows people to access the destinations and services they want or need and helps them maintain social relations, participate in society, and maintain their sense of citizenship and belonging in their community (Davey 2007; Musselwhite 2018).

In this chapter, I advance the idea of a transport system as part of the societal structures that construct and shape mobility opportunities and barriers, and, in turn, social inclusion or exclusion. I argue that a transport system is a societal structure that can support good ageing and the social inclusion of older adults, and that some major problems in, and barriers to, transport mobility for older adults are the consequences of ageist or otherwise non-age-acknowledging policies and priorities.

This chapter begins with an overview of the relation between transport mobility and well-being in late-life. Next, I discuss transport as a societal structure affecting late-life inclusion and analyse the mismatch between current structures and actual needs. Finally, I discuss the interconnections between transport and other domains of social inclusion/exclusion.

\footnotetext{
A. Siren $(\bowtie)$

The Danish Center for Social Science Research, Copenhagen, Denmark

e-mail: anu@ vive.dk 


\subsection{Transport Mobility and Well-Being in Late-Life}

Transport mobility is an important part of older individuals' well-being. Early scholarship has defined an individual's ability to manage transportation as one of the main areas in instrumental activities of daily living (Lawton and Brody 1969), and research has shown that the ability to leave the home and independently move about are among the essential aspects of well-being in late-life (Farquhar 1995). Research has also found that mobility loss in late-life causes depression and feelings of social isolation (e.g. Fonda et al. 2001; Qin et al. 2019).

Mobility is a highly appreciated value in our society, partly because it enables people to engage in social relations and obtain a feeling of proximity (Urry 2002), and partly because it enables people to access the necessities of contemporary life, e.g. work, shopping and leisure activities. Mobility and travel greatly regulate inclusion and exclusion in terms of social interaction, out-of-home activities and experiences, and civic power.

Nevertheless, mobility carries more than merely instrumental value and entails more than the necessities or preconditions for access and social encounters. Mobility plays an important part in constructing the self in social and other settings and in giving people pleasure and enjoyment (Musselwhite and Haddad 2010). Indeed, in their model of the different levels of older adults' mobility needs, Musselwhite and Haddad (ibid.) emphasise the affective and aesthetic needs related to travel, arguing that these needs have received only a minimum of awareness from policy makers and transport planners.

Because transport mobility in late-life entails both reaching desirable or necessary destinations or services and obtaining social connectedness, we need to extend our view beyond accessibility issues. Accessibility problems caused by barriers to transport, such as the lack of access to shopping or services, can be targeted through single-domain interventions, such as online shopping, telemedicine and care at home. However, to prevent the loss of social inclusion and citizenship (due to unmet instrumental, affective or aesthetic needs) caused by lack of transportation requires a broader understanding of transport as a social structure.

\subsection{Transport as a Societal Structure}

Transportation is a culturally and socially shaped dynamic system in which the users and the infrastructure are inter-related. The way that the transportation system is designed, arranged and managed reflects both our societal values and everyday life. In principle, a transport system is an arena open to all members of society, with everyone being able to arrange his or her travel in the most convenient and preferable way. According to contemporary travel models, transport is the medium needed for individuals to satisfy their travel demand (e.g. Axhausen and Gärling 1992). However, if transport is discerned as a space that both constructs and is constructed, 
one can challenge its commonly understood meaning as a mere platform for activities.

Foucault, as one of the first scholars to analyse public spaces, power relations and related meanings, has argued that constructed and built spaces hold different meanings for different users (e.g. Foucault 1977). In his view, a built space such as transport systems not only regulates and constructs social relations and interactions between people but also produces cultural meanings. De Certeau (1984) has analysed space both as an intersection of mobile elements and as a platform for spatial practices. He argues that the meanings of a given space are specifically constructed in the process of practicing spatial actions.

Given the constructed and constructing nature of the transport system, questions involving power, inclusion and exclusion arise. Who is to construct and design the system, and for whom? How does the system influence the lives of different groups of people? Can it, indeed, be an arena for everyone if the opportunities for influencing its construction are not equal?

Older adults' marginal position in transport policy and planning may be a consequence of the predominant focus on utilitarian travel demand in transport planning scholarship. A conventional tenet in transportation research is that travel is the manifest choice derived from an individual's activities (e.g. Axhausen and Gärling 1992) and that therefore the most common activities in a society are the most important for planning that society's transport system. Older adults' travel and mobility needs tend to be less utilitarian, less predictable and more discretionary. Parkhurst et al. (2014) have argued that the economy-efficiency approach - dominant in transport policy and planning - prioritises travel that creates net benefits within the formal economy (i.e. work- related and commercial travel). Discretionary travel, i.e. trips made for social purposes or for the sake of travel itself, receives lesser priority.

\subsection{Transport and Social Exclusion in Late-Life}

Previous studies have provided evidence on how lack of transport is a direct barrier to participation in activities and social encounters. Availability of transport has been found to regulate older adults' employment (Anderson et al. 2013), participation in education (Patterson et al. 2016), grocery shopping (Hare et al. 2001), participation in cultural and religious activities (Johnson et al. 2011; Sowa et al. 2016).

Other studies have identified factors contributing to the likelihood of having transport disadvantage that leads or adds to social exclusion in old-age. Older adults who lack a driver license, are in poorer health, are older or women, and have lower income, lower levels of mobility and higher levels of unfulfilled mobility needs (Siren and Hakamies-Blomqvist 2004). People living in rural areas have a likelihood of transport disadvantage (Higgs and White 1997), mainly because they depend solely on private car transportation (Glasgow and Blakely 2000; see also Cholat and Dacanto this volume). Nevertheless, as Engels and Liu (2011) point out, older adults in metropolitan areas with insufficient public transport can also be 
highly dependent on cars, leading to transport disadvantage among those with no option of driving (or of being driven by others).

In general, the lack of a driving option is problematic from a social inclusion standpoint, and particularly so in North America and Australia, where stopping driving can be associated with a significant decrease in social integration (Mezuk and Rebok 2008). Haustein and Siren (2014) have shown that older adults without a driving option experienced limited mobility, and this disparity remained even if those involved lived near public transport.

Some research has more closely analysed how transport mobility contributes to inclusion in older-age. Davey (2007) has suggested that different types of mobility have different implications for inclusion. While necessity travel, for example for health care or grocery shopping, is experienced as more "legitimate", discretionary travel for enjoyment or "leisure" is viewed as less legitimate. Consequently, older adults without personal transportation are hesitant to ask family or friends for rides for discretionary purposes.

\subsection{Structural Lag and Transport}

The traditional view in transport mobility research - that travel is "reasoned" behaviour (e.g. Bamberg et al. 2003) - emphasises individual choice as the main regulator of personal travel. From this viewpoint, all people in principle have the same choicemaking opportunities: although choice-based models recognise that a number of factors influence the array of choices (e.g. car access, spatial context, or physical limitations), these models locate these factors in the domain of the individual. In other words, these models view limitations in the array of choices as a unique set of features for each individual, rather than features of a constructed institution-in this case, the transport system.

However, just as social studies on disability argues that disability, rather than being a biological fact, is a construct of the intersection of demands and lack of support in the environments people live in (Wendell 1996, p. 58), one can view agerelated mobility problems as socially constructed through systems, policies, and priorities in the transport area. Some mobility limitations emerge only in the intersection of current structures and the needs of system users, a problem that demands a better understanding and acknowledgement of the interplay between structures and individuals. If one lays aside the conventional assumption that the mobility problems of older adults are caused solely by the effects of old-age (e.g. physical frailty), one might realise that they are also the outcome of a mismatch between the transportation system and the transport needs and experiences of older adults.

In 1994, Riley and her colleagues introduced the concept of "structural lag" to describe the mismatch between structures and people's capabilities, needs and aspirations, in a context of rapid social change. They argued that: 
'While the twentieth century has experienced a revolution in human development and ageing, there has been no comparable revolution in the role structures of society to keep pace with the changes in the ways people grow up and grow old. The lag involves not only institutional and organizational arrangements, but also the many aspects of culture that, in addition to being internalised by people, are built into role expectations and societal mores and laws'. (Riley et al. 1994, p. 16-17)

The concept of structural lag is useful for investigating the area of transport and late-life. In the past 100 years, throughout the industrialised world, transport systems, mobility patterns and societal demands for mobility have changed tremendously (Siren and Sørensen 2015). Mobility and travel are essential parts of contemporary life (Urry 2002), people today travel more than ever, and mobility is deeply embedded in western culture and people's everyday lives. For older adults, the travel patterns have changed even more rapidly across time than for other groups.

Improved health conditions, active lifestyles, increased access to cars and, for some groups, higher income and education create greater possibilities and needs for more varied activities and extended travelling than for the previous generations of older adults. These expectations are especially associated with the baby boomer generation (Coughlin 2009).

Studies have demonstrated higher travel activity, driver licensing rates, car access and car use in each successive cohort of older adults (e.g. Newbold et al. 2005; Hjorthol et al. 2010). Older people's travel has increased in the social/leisure category in particular (Arentze et al. 2008) and for car trips in general (e.g. Newbold et al. 2005; Delbosc and Currie 2011).

Given the tremendous change in older adults' travel, the question arises as to whether the structures surrounding late-life mobility have adapted to the change. The answer is largely no. Transport-related structures and norms still lag behind rapidly changing late-life. While older adults are increasingly encouraged to age actively and productively by, for example extending their working lives (Walker 2002), the transport policies are not aligned with these goals. Driver licenses in many countries expire at age 55-70 years as a default and require renewal if the driver wishes to continue driving (Siren and Haustein 2015). The free or subsidised public transport entitlements for older adults are often valid only in during off-peak hours (Mackett 2014), indicating that older adults are expected to have travel needs at different times than everyone else.

Among the policies affecting older adults' mobility opportunities, the one most obviously dated is the age-related regulation of driver licenses. While for mature drivers the chronological age is only a weak predictor of safe driving performance, licensing policies based on age are widely used in most European countries and many US and Australian states (Langford et al. 2004; Dickerson et al. 2014; Siren and Haustein 2015). In their review, Siren and Haustein (2015) conclude that the policies are coercive because they require both frequent renewals and proof of driver fitness in connection with renewal. Siren and Haustein (ibid.) also note that having these types of coercive policies signal that society finds car-driving by older citizens a questionable, even suspect, activity, and they may encourage people to give up driving even when they are still fit to drive. 
Rather than being evidence-based, these age limits of renewal and medical assessment are usually intuitive and set ad hoc. They are not based on any current knowledge on age or crash propensity or risk (Langford et al. 2006), nor on epidemiological knowledge on the age-related incidence of diseases influencing driving skills (e.g. Alzheimer's Disease International 2008). Rather, they reflect the aspirations, behaviours and capabilities of older adults in terms of the way "old-age" was viewed 50 or 60 years ago.

\subsection{Adjusting the Structures to Alleviate the Lag}

The World Health Organization's “age-friendly movement” (WHO 2007) has encouraged age-friendly adjustments to transportation systems, with a focus on, for example availability, affordability, age-friendly design, safety and comfort. However, perhaps because these guidelines have a global focus, they have not been implemented in wider social policies on local or national levels, especially in western industrialised societies. Moreover, as these guidelines do not directly address the societal implications of late-life mobility, they have been mostly used in isolated small-scale initiatives such as redesigning buses (Broome et al. 2013) or improving public transport service in particular communities (e.g. Shiau and Huang 2014).

Since 2008 older adults in Britain have been entitled to a pass enabling them to travel by bus during off-peak hours. The objectives of introducing the concessionary pass were social, aimed at improving the lives of older people by improving their access to services and increasing social inclusion. From the perspective of structural lag, the concessionary bus pass does not appear to be an active adjustment of structures to shifting demographics or emerging needs. Rather, it appears to be a social benefit compensating for the individual deficits bundled under an assumed common denominator, "old-age". Mackett (2014) argues that while bus travel among older adults has increased and that the overall impacts are positive, the bus pass is being used only by a small group of eligible users, partly due to the availability of highquality bus services across Britain.

The private car is the safest and most convenient mode of transport for older adults (OECD 2000), and it plays an important role in their everyday mobility. Nevertheless, licensing policies tend to work against driving in late-life. Ageism, vested interests and biased conceptions of the ageing process all contribute to society's eagerness to regulate older drivers' rights to drive (O'Neill 2012). While scholars have called for more evidence-based policies (Desapriya et al. 2012; Salmi et al. 2014), no major change has yet occurred in measuring the returns on the societal investments made for these policies.

Only few countries have reviewed their policies on licensing and age in response to changing demographics and travel patterns. Sweden, which has never had agebased licensing, reviewed its policy in 2018 and the potential safety gains of implementing driver license regulations (Skyving et al. 2018). The analysis, based on all Swedish road accidents involving older adult drivers with medical conditions, 
showed no potential safety gains from screening for these conditions. Consequently, Sweden decided to continue without age-based regulations. Although Denmark used to have age-based policies, it decided to remove them in 2017 after a review. According to parliamentary documents (Folketinget 2017), the change was based on a review of research evidence, assessment of the costs associated with having all older drivers screened for driving fitness, the administrative burden of licensing offices (given the large cohorts of older drivers), and the financial and psychological burden on older adults having to undergo the screening. While the overall rationale was economic, based on cost-benefit analyses, additional political motives might have included the growing voting population of older voters.

In the US, seeking individual transport solutions for non-driving older adults is more common than in Europe. Independent Transport Network (ITN) America, started specifically as a response to a transportation system incapable of meeting the needs of an ageing population (Freund 2003). In many ways, the ITN concept is a non-profit predecessor of Uber, Lyft and sharing economy-based services alike. ITN provides a sharing-economy platform for (predominately volunteer and mainly mature) drivers to provide transportation services for older and visually impaired adults that no longer are able to drive themselves. Interestingly, such a bottom-up service appears to capture the need for actively adjusting structures to match changing needs better and more quickly than any public policy. While not directly transferable to transport contexts outside the US, such sharing economy- or local community-driven models might work in rural and other car-dependent areas in Europe if they were modified to the local context (see also Shergold and Parkhurst 2012).

\subsection{Interconnections Between the Domains of Social Exclusion and Knowledge Gaps}

As a review of the international literature shows, transport is a cross-cutting element in social exclusion and in some cases can serve as a principal driver of exclusionary experiences in late-life. Access to transportation has direct implications for economic inclusion and exclusion (i.e. being able to access work) and inclusion in or exclusion from social relations, services and civic participation. Economic exclusion and exclusion from social relations in turn influence transport accessibility, as personal transport requires financial or social resources or both (e.g. paying for transport, keeping a car, asking people for rides) [see Cholat and Dacanto for a discussion of these factors in relation to reverse mobilities].

Understanding the interconnections with the spatial dimensions of exclusion is critical, as rural areas have a more restricted palette of transport options, combined with longer distances between settled areas and service centres, and lower population density. A framework for understanding rural transport disadvantage has been suggested by Marr (2015). His main argument is that transport disadvantage is not 
dichotomous but rather a continuum, and that various factors, such as demographic characteristics or socio-economic status, determine the levels of disadvantage in rural areas. Similarly, Grant et al. (2010) have argued that the planning strategies for increasing transport possibilities for older adults need to go beyond mere density. They found that the walking behaviour among older adults was not solely influenced by physical design; rather, an interconnection existed between physical walkability and neighbourhood socio-economic characteristics.

Because of the intersecting domains of exclusion, Audirac (2008) argues that (spatial) planning has the potential to reduce several types of old-age related social exclusion. However, to fully integrate the various domains related to social exclusion, we need to look beyond accessibility and the instrumental value of transport. As this chapter has demonstrated, a transport system is not merely a travel platform derived from individual choices. The priorities that shape the transport system and guide planning, design and policies are based on culturally and socially shaped ideas within a society.

We thus need to take a closer look at the goals and priorities in transport, analysing not only the origins of these ideas but also their implications for different demographic groups. Do initiatives for greener transport favour some groups at the cost of others? Does an efficient transport system mainly serve the needs of those belonging to the formal economy? We also need to ask whether we should view transport systems as a societal welfare structure, aimed at producing benefits beyond the transport sector or formal economy. If transport is understood in this way, planning may become a tool for reducing social exclusion - but only if the stated goals are set beyond accessibility, to include wider social inclusion, belonging and civic participation.

\subsection{Conclusion}

The current framing of transport-related social exclusion predominantly takes place within the planning of transport services and physical environments. While planning for accessibility is important, the lack of a broader conceptual understanding of transport-related social exclusion is clear, and the gerontological scholarship and wider understanding of social exclusion more generally is scarce. To fully understand the role of transport in late-life social exclusion, we must go beyond the transport system and view transport-related social exclusion as a societal issue, because various domains (e.g. social participation) are interrelated with transport. We need also to look beyond mere designs and services to focus on structures, including ageist legislation that causes transport-related exclusion, such as coercive and ageist driver licensing policies.

Mobility has great impacts on people's lives, with quantifiable gains from latelife mobility, in terms of psychological, physical and community benefits (Spinney et al. 2009). Sadly, transport deficits are often viewed simply as an outcome of exclusion from specific services. In this chapter, I have demonstrated the 
multidimensionality of transport-related exclusion and transport's interrelations with other domains of exclusion. Policymakers and scholars alike need to acknowledge these cross-sectoral benefits and relations, and to consider the role of transport systems beyond the mere equipment for and logistics of transporting people and goods.

\section{Editors' Postscript}

Please note, like other contributions to this book, this chapter was written before the COVID-19 pandemic of 2020. The book's introductory chapter (Chap. 1) and conclusion (Chap. 34) consider some of the key ways in which the pandemic relates to issues concerning social exclusion and ageing.

\section{References}

Alzheimer's Disease International. (2008).The prevalence of dementia worldwide. http://www.alz. co.uk/adi/pdf/prevalence.pdf.

Anderson, K. A., Richardson, V. E., Fields, N. L., \& Harootyan, R. A. (2013). Inclusion or exclusion? Exploring barriers to employment for low-income older adults. Journal of Gerontological Social Work, 56(4), 318-334. https://doi.org/10.1080/01634372.2013.777006.

Arentze, T., Timmermans, H., Jorritsma, P., Olde Kalter, M.-J., \& Schoemakers, A. (2008). More grey hair-But for whom? Scenario-based simulations of elderly activity travel patterns in 2020. Transportation, 35(5), 613-627. https://doi.org/10.1007/s11116-008-9170-z.

Audirac, I. (2008). Accessing transit as universal design. Journal of Planning Literature, 23(1), 4-16.

Axhausen, K. W., \& Gärling, T. (1992). Activity-based approaches to travel analysis: Conceptual frameworks, models, and research problems. Transport Reviews, 12(4), 323-341. https://doi. org/10.1080/01441649208716826.

Bamberg, S., Ajzen, I., \& Schmidt, P. (2003). Choice of travel mode in the theory of planned behavior: The roles of past behavior, habit, and reasoned action. Basic and Applied Social Psychology, 25(3), 175-187. https://doi.org/10.1207/S15324834BASP2503_01.

Broome, K., Worrall, L., Fleming, J., \& Boldy, D. (2013). Evaluation of age-friendly guidelines for public buses. Transportation Research Part A: Policy and Practice, 53, 68-80. https://doi. org/10.1016/j.tra.2013.05.003.

Coughlin, J. F. (2009). Longevity, lifestyle, and anticipating the new demands of aging on the transportation system. Public Works Management \& Policy, 13(4), 301-311. https://doi.org/1 $0.1177 / 1087724 X 09335609$.

Davey, J. A. (2007). Older people and transport: Coping without a car. Ageing and Society, 27(1), 49-65. https://doi.org/10.1017/S0144686X06005332.

De Certeau, M. (1984). Practice of everyday life. Berkeley: University of California Press.

Delbosc, A., \& Currie, G. (2011). Transport problems that matter - Social and psychological links to transport disadvantage. Journal of Transport Geography, 19(1), 170-178. https://doi. org/10.1016/j.jtrangeo.2010.01.003.

Desapriya, E., Ranatunga, Y., \& Pike, I. (2012). We need evidence based tools to identify medically at risk drivers. BMJ, 345, e7087-e7087. https://doi.org/10.1136/bmj.e7087. 
Dickerson, A. E., Meuel, D. B., Ridenour, C. D., \& Cooper, K. (2014). Assessment tools predicting fitness to drive in older adults: A systematic review. American Journal of Occupational Therapy, 68(6), 670-680. https://doi.org/10.5014/ajot.2014.011833.

Engels, B., \& Liu, G.-J. (2011). Social exclusion, location and transport disadvantage amongst non-driving seniors in a Melbourne municipality, Australia. Journal of Transport Geography, 19(4), 984-996. https://doi.org/10.1016/j.jtrangeo.2011.03.007.

Farquhar, M. (1995). Elderly people's definitions of quality of life. Social Science \& Medicine, 41(10), 1439-1446. https://doi.org/10.1016/0277-9536(95)00117-P.

Folketinget. (2017). L 201 Forslag til lov om andring af fardselsloven. Copenhagen: Folketinget.

Fonda, S. J., Wallace, R. B., \& Herzog, A. R. (2001). Changes in driving patterns and worsening depressive symptoms among older adults. The Journals of Gerontology Series B: Psychological Sciences and Social Sciences, 56(6), S343-S351.

Foucault, M. (1977). Discipline \& Punish: The birth of the prison. London: Penguin Books.

Freund, K. (2003). Independent transportation network: The next best thing to driving. Generations, $27(2), 70-71$.

Glasgow, N., \& Blakely, R. M. (2000). Older nonmetropolitan residents' evaluations of their transportation arrangements. Journal of Applied Gerontology, 19(1), 95.

Grant, T. L., Edwards, N., Sveistrup, H., Andrew, C., \& Egan, M. (2010). Inequitable walking conditions among older people: Examining the interrelationship of neighbourhood socioeconomic status and urban form using a comparative case study. BMC Public Health, 10, 677-692. https://doi.org/10.1186/1471-2458-10-677.

Hare, C., Kirk, D., \& Lang, T. (2001). The food shopping experience of older consumers in Scotland: Critical incidents. International Journal of Retail \& Distribution Management, 29(1), 25. https://doi.org/10.1108/09590550110366343.

Haustein, S., \& Siren, A. (2014). Seniors' unmet mobility needs - how important is a driving licence? Journal of Transport Geography, 41, 45-52. https://doi.org/10.1016/j.jtrangeo.2014.08.001.

Higgs, G., \& White, S. D. (1997). Changes in service provision in rural areas. Part 1: The use of GIS in analyzing accessibility to services in rural deprivation research. Journal of Rural Studies, 13(4), 441.

Hjorthol, R. J., Levin, L., \& Siren, A. (2010). Mobility in different generations of older persons. The development of daily travel in different cohorts in Denmark, Norway and Sweden. Journal of Transport Geography, 18(5), 624-633.

Johnson, V., Currie, G., \& Stanley, J. (2011). Exploring transport to arts and cultural activities as a facilitator of social inclusion. Transport Policy, 18(1), 68-75. https://doi.org/10.1016/j. tranpol.2010.06.001.

Langford, J., Fitzharris, M., Newstead, S., \& Koppel, S. (2004). Some consequences of different older driver licensing procedures in Australia. Accident Analysis \& Prevention, 36(6), 993-1001. https://doi.org/10.1016/j.aap.2003.11.003.

Langford, J., Methorst, R., \& Hakamies-Blomqvist, L. (2006). Older drivers do not have a high crash risk - A replication of low mileage bias. Accident Analysis and Prevention, 38(3), 574-578.

Lawton, M. P., \& Brody, E. M. (1969). Assessment of older people: Self-maintaining and instrumental activities of daily living. The Gerontologist, 9(3 Part 1), 179-186. https://doi. org/10.1093/geront/9.3_Part_1.179.

Mackett, R. (2014). Has the policy of concessionary bus travel for older people in Britain been successful? Case Studies on Transport Policy, 2(2), 81-88. https://doi.org/10.1016/j. cstp.2014.05.001.

Marr, E. (2015). Assessing transportation disadvantage in rural Ontario, Canada: A case study of Huron County. Journal of Rural \& Community Development, 10(2), 100-120.

Mezuk, B., \& Rebok, G. W. (2008). Social integration and social support among older adults following driving cessation. Journals of Gerontology Series B: Psychological Sciences \& Social Sciences, 63B(5), S298-S303.

Musselwhite, C. (2018). Community connections and Independence in later life. In E. Peel, C. Holland, \& M. Murray (Eds.), Psychologies of ageing (pp. 221-252). Cham: Palgrave Macmillan Ltd. 
Musselwhite, C., \& Haddad, H. (2010). Mobility, accessibility and quality of later life. Quality in Ageing and Older Adults, 11(1), 25-37. https://doi.org/10.5042/qiaoa.2010.0153.

Newbold, K. B., Scott, D. M., Spinney, J. E. L., Kanaroglou, P., \& Páez, A. (2005). Travel behavior within Canada's older population: A cohort analysis. Journal of Transport Geography, 13(4), 340-351. https://doi.org/10.1016/j.jtrangeo.2004.07.007.

O'Neill, D. (2012). More mad and more wise. Accident Analysis \& Prevention, 49, 263-265. https://doi.org/10.1016/j.aap.2012.01.010.

OECD. (2000). Transport and ageing of the population. Paris: Organization for Economic Cooperation \& Development.

Parkhurst, G., Galvin, K., Musselwhite, C., Phillips, J., Shergold, I., \& Todres, L. (2014). Beyond transport: Understanding the role of mobilities in connecting rural elders in civic society. In C. Hennesey, R. Means, \& V. Burholt (Eds.), Countryside connections: Older people, community and place in rural Britain (pp. 125-157). Bristol: Policy Press.

Patterson, R., Moffatt, S., Smith, M., Scott, J., Mcloughlin, C., Bell, J., \& Bell, N. (2016). Exploring social inclusivity within the University of the Third age (U3A): A model of collaborative research. Ageing \& Society, 36(8), 1580-1603. https://doi.org/10.1017/S0144686X15000550.

Qin, W., Xiang, X., \& Taylor, H. (2019). Driving cessation and social isolation in older adults. Journal of Aging and Health, 1-19. https://doi.org/10.1177/0898264319870400.

Riley, M. W., Kahn, R. L., \& Foner, A. (1994). Age and structural lag. New York: Wiley.

Salmi, L. R., Leproust, S., Helmer, C., \& Lagarde, E. (2014). Assessing fitness to drive in the elderly and those with medical conditions: Guidelines should specify methods and evidence. Injury Prevention, 20(3), 210-212. https://doi.org/10.1136/injuryprev-2013-040972.

Shergold, I., \& Parkhurst, G. (2012). Transport-related social exclusion amongst older people in rural Southwest England and Wales. Journal of Rural Studies, 28(4), 412-421. https://doi. org/10.1016/j.jrurstud.2012.01.010.

Shiau, T. A., \& Huang, W. K. (2014). User perspective of age-friendly transportation: A case study of Taipei City. Transport Policy, 36, 184-191. https://doi.org/10.1016/j.tranpol.2014.08.010.

Siren, A., \& Hakamies-Blomqvist, L. (2004). Private car as the grand equaliser? Demographic factors and mobility in Finnish men and women aged 65+. Transportation Research Part F: Traffic Psychology and Behaviour, 7(2), 107-118.

Siren, A., \& Haustein, S. (2015). Driving licences and medical screening in old age: Review of literature and European licensing policies. Journal of Transport and Health, 2(1), 68-78. https:// doi.org/10.1016/j.jth.2014.09.003.

Siren, A., \& Sørensen, C. H. (2015). Immense changes in traffic - Considerable stability in discourses: Road speed in Danish parliamentary documents 1900-2010. Transport Policy, 40, 1-7. https://doi.org/10.1016/j.tranpol.2015.02.005.

Skyving, M., Forsman, A., \& Dukic Willstrand, T. (2018). Samband mellan sjukdomar och äldre bilförares inblandning i trafikolyckor. Stockholm: Transportstyrelsen.

Sowa, A., Golinowska, S., Deeg, D., Principi, A., Casanova, G., Schulmann, K., Ilinca, S., Rodrigues, R., Moreira, A., \& Gelenkamp, H. (2016). Predictors of religious participation of older Europeans in good and poor health. European Journal of Ageing, 13(2), 145-157. https:// doi.org/10.1007/s10433-016-0367-2.

Spinney, J. E. L., Scott, D. M., \& Newbold, K. B. (2009). Transport mobility benefits and quality of life: A time-use perspective of elderly Canadians. Transport Policy, 16(1), 1-11. https://doi. org/10.1016/j.tranpol.2009.01.002.

Urry, J. (2002). Mobility and proximity. Sociology, 36(2), 255-274. https://doi.org/10.117 $7 / 0038038502036002002$.

Walker, A. (2002). A strategy for active ageing. International Social Security Review, 55(1), $121-139$.

Walsh, K., Scharf, T., \& Keating, N. (2017). Social exclusion of older persons: A scoping review and conceptual framework. European Journal of Ageing, 14(1), 81-98. https://doi.org/10.1007/ s10433-016-0398-8.

Wendell, S. (1996). The rejected body: Feminist philosophical reflections on disability. New York: Routledge/Taylor \& Francis Group.

WHO. (2007). Global age-friendly cities: A guide. Geneva: WHO. 
Open Access This chapter is licensed under the terms of the Creative Commons Attribution 4.0 International License (http://creativecommons.org/licenses/by/4.0/), which permits use, sharing, adaptation, distribution and reproduction in any medium or format, as long as you give appropriate credit to the original author(s) and the source, provide a link to the Creative Commons license and indicate if changes were made.

The images or other third party material in this chapter are included in the chapter's Creative Commons license, unless indicated otherwise in a credit line to the material. If material is not included in the chapter's Creative Commons license and your intended use is not permitted by statutory regulation or exceeds the permitted use, you will need to obtain permission directly from the copyright holder. 